RICYDE. Revista Internacional de Ciencias del Deporte doi: $10.5232 /$ ricyde

Rev. int. cienc. deporte

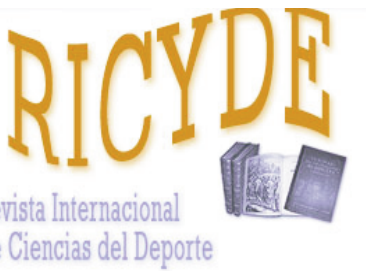

RICYDE. Revista Internacional de Ciencias del Deporte VOLUME XIV - YEAR XIV

Pages:101-110 ISSN:1885-3137

Issue: 52 - April - 2018

\title{
Relationship between test of postural control and strength and ability tests in basketball players \\ Relación entre las pruebas de control postural y las pruebas de fuerza y habilidad en jugadores de baloncesto
}

\author{
Abbas Asadi ${ }^{1}$ \& Hamid Arazi ${ }^{2}$ \\ 1.Department of Physical Education and Sport Sciences, Payame Noor University, Iran \\ 2.Department of Exercise Physiology, Faculty of Sport Sciences, University of Guilan, Rasht, Iran
}

\begin{abstract}
This study investigated the relationship between performance tests (i.e., jumping ability, strength, sprint and change of direction ability) and dynamic postural control in young basketball players. Twenty-three young basketball players participated in this study and performed measurements of dynamic balance (Star Excursion Balance Test [SEBT]), countermovement jump (CMJ), broad long jump (BLJ), 4×9-m shuttle run, agility $T$ test (TT), Illinois agility test (IAT), 20-m sprint and lower extremity muscle strength. Significant association was observed between balance (at medial direction) and strength performance $(r=0.523, p<0.05)$. Significant positive correlations were detected between directions of SEBT and BLJ $(r=-0.466$ to $-0.479, p<0.05), 4 \times 9-m$ shuttle run $(r=-0.403$ to $0.486, p<0.05)$, TT $(r=-0.410, p<0.05)$, IAT $(r=0.435, p<0.05)$ and sprint $(r=-0.402$ to 0.452 , $p<0.05$ ). Postural control is more in relation to change of direction ability, sprint and power performance in basketball athletes.
\end{abstract}

Key words: balance strength; muscle performance, youth

\section{Resumen}

Este estudio investigó la relación entre las pruebas de rendimiento y el control postural dinámico en jóvenes jugadores de baloncesto. Veintitrés jóvenes jugadores de baloncesto participaron en este estudio y realizaron mediciones de equilibrio dinámico (Prueba de Balance de Excursión Estrella [SEBT]), salto de contramovimiento (CMJ), salto largo en longitud (BLJ), lanzamiento de $4 \times 9 \mathrm{~m}$, test T de agilidad (TT), prueba de agilidad de Illinois (IAT), sprint de $20 \mathrm{~m}$ y fuerza muscular de las extremidades inferiores. Se observó una asociación significativa entre el equilibrio (en la dirección medial) y el rendimiento de la fuerza $(r=0.523, p<0.05)$. Se detectaron correlaciones positivas significativas entre las direcciones de SEBT y BLJ $(r=-0,466$ a $-0,479, p<0,05)$, carrera con cambios de sentido de $4 \times$ $9 \mathrm{~m}(r=-0,403$ a $0,486, p<0,05), \pi(r=0,410, p<0,05)$, IAT $(r=0,435, p<0,05)$ y sprint $(r=-$ $0,402$ a $0,452, p<0,05)$. El control postural está altamente correlacionado con la capacidad de cambio de dirección, sprint y el rendimiento de potencia en los atletas de baloncesto.

Palabras clave: equilibrio; fuerza; rendimiento muscular; juventud 
Asadi, A., \& Arazi, H. (2018). Relationship between test of postural control and strength and ability tests in basketball players. RICYDE. Revista internacional de ciencias del deporte, 52(14), 101-110.

\section{Introduction}

$\mathrm{P}$ ostural control (PC) deficits is an important risk factor for sports-related injuries in young athletes (Wang et al. 2006; Fousekis et al., 2011), and Wang et al. (2006) indicated that variations in postural control could be in relation to occurrence of ankle injuries in high school basketball players. In addition to ankle injuries, anterior cruciate ligament (ACL) injuries are common in basketball athletes (Arendt et al. 1995). The reported incidence of ACL injury is as high as 1.6 per 1,000 player-hours for elite players in team matches (Mylelbust et al., 1997) and it seems that postural control deficits play a critical role to increase the injury risk. On the other hand, poor PC is associated with injury or falls in athletes and consequently is considered to be a critical component of common motor skills (McGuine et al. 2000; Asadi et al., 2015). In addition, deficits in lower extremity muscle strength/performance were reported to be a significant intrinsic risk factor for noncontact quadriceps and hamstrings strains and ACL tearing in young players (Fousekis et al., 2011; Khayambashi et al., 2015).

From a therapist's or a practitioner's point of view, knowledge about the relationship between postural control and lower extremity muscle strength/performance may be important for both the identification of persons with an increased fall/injury risk and the development of fall/injury-preventive training programs. Moreover, determining the association between PC performance and maximal-intensity exercise tests could provide scientific rationales for injury risk assessment and for the development of specifically tailored injury prevention and rehabilitation programs in young athletes (Wang et al. 2006; Fousekis et al., 2011; Asadi et al., 2015).

Association between measures of maximal-intensity exercise performance tests have been studied in basketball athletes (Latin et al., 1994; Erculj et al., 2010; Shalfawi et al. 2011) and the authors reported relationship between change of direction ability, sprint and jump performance. In terms postural control, study results are less consistent and little is known about the relationship between postural control performance and maximal-intensity exercise tests in basketball athletes. In the study by Holviala et al. (2006) associations between variables of strength and several balance capacities (e.g., bipedal stance) were reported ranging from $r=-0.66$ to +0.90 . Weirich et al. (2010) reported that most measures of balance (i.e., monopedal stance, tandem walk, etc.) were only weak or moderately related to predictor variables such as quadriceps, hip extensors, and hamstrings strength. Recently, Muehlbauer et al. (2013) reported no significant associations between variables of static/dynamic balance and isometric strength, countermovement jump and power in young adults and stated that isometric strength, power and static/dynamic balance are independent of each other.

The reason for this discrepancy in the literature could be probably due to different research design applied and different methods for the assessment of balance and exercise performance tests. There is paucity in the literature regarding the relationship between dynamic balance (PC) and jump performance, change of direction ability, sprint or strength in young basketball athletes. In other words, further research is needed to better determine the relationship between balance and lower extremity muscle strength/performance in athletes. Moreover, most previous studies used laboratory tests (i.e., balance platform to assess PC), but the novel approach in this study was field tests (i.e., Star Excursion Balance Test [SEBT] to measure PC). In general, the reliability and validity of the laboratory tests are greater than field tests, but the field approach tests are often more valid because of their greater specificity to sport events 15. Therefore, the objective of this study was to determine the relationship between different directions of SEBT (dynamic balance or PC) and jump performance, change of direction ability, sprint and lower extremity muscle strength in young basketball players. 
Asadi, A., \& Arazi, H. (2018). Relationship between test of postural control and strength and ability tests in basketball players. RICYDE. Revista internacional de ciencias del deporte, 52(14), 101-110.

\section{Methodology}

\section{Participants}

Twenty-three national-level young male basketball players (age $19.7 \pm 0.6 \mathrm{y}$; height $182.2 \pm$ $8.4 \mathrm{~cm}$; body mass $75.1 \pm 10.4 \mathrm{~kg}$ and training age $6.1 \pm 1.7 \mathrm{y})$ from a single regional basketball team in Iran volunteered to participate in this study. The subjects were volunteers from competitive Division 1 club basketball program. All athletes completed a self-report health history questionnaire and signed a written informed consent before testing. All athletes were also screened for lower extremity bone and joint injuries and abnormalities by physician. No one had any history of musculoskeletal, neurological, or orthopedic disorder that might have affected their ability to perform balance and or maximal-intensity performance tests. The procedures were approved by the Institutional Ethics Review Committee of the University in accordance with the current national and international laws and regulations governing the use of human subjects (Declaration of Helsinki II).

\section{Study design}

The data collection for all athletes was completed related to the pre-season. One week before initiation of testing, all athletes reported to basketball gym with a wood floor. During this session, the basketball players were familiarized with Star Excursion Balance Test (SEBT) and maximal-intensity exercise performance tests which described by certificated Strength and Conditioning coach. All athletes attended two testing sessions separated with 72 hours. The first test session evaluated SEBT, jump and sprint performance. The second test session involved change of direction ability tests and maximal strength. Before the tests, the athletes carried out a standardized warm-up consisting of 10 minutes submaximal running followed by light stretching and a specific warm-up (3 to 4 trials for each test) with the assessment exercises. Additionally, care was taken to allow sufficient rest between all the tests to limit the effects of fatigue on subsequent tests. To determine reliability, two measurements were made in 15 athletes, 72 hours apart (Figure 1).

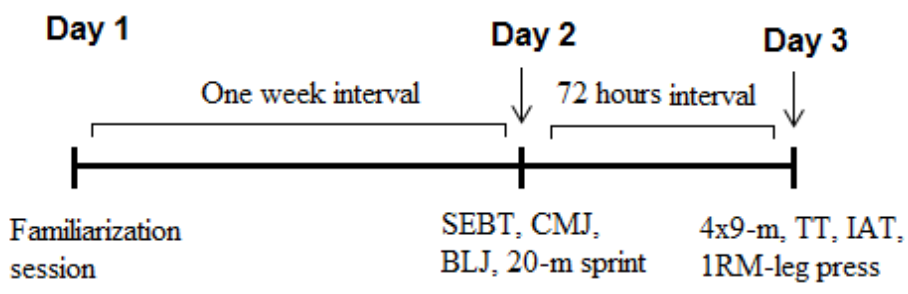

Figure 1. Study design. $\downarrow$ testing day.

\section{Protocol}

Height was measured using a wall mounted stadiometer (Seca 222, Terre Haute, IN) recorded to the nearest $0.5 \mathrm{~cm}$. Body mass was measured to the nearest $0.1 \mathrm{~kg}$, using a digital scale (Tanita, BC-418MA, Tokyo, Japan). To normalize the SEBT reach distances (dividing the distance reached by leg length then multiplying by 100), leg length was quantified as the distance $(\mathrm{cm})$ from the anterior superior iliac spine to the center of the ipsilateral medial malleolus with the athletes in a supine position (Asadi et al., 2015).

Jump performance was measured by using countermovement jump (CMJ) and broad long jump (BLJ). A Vertec device (Power System, Knoxville, Tennessee) was used to measure the height of the CMJs to the nearest one $\mathrm{cm}$. To prepare the Vertec, the athletes stood under it with their feet together and heels on the ground and reached with their dominant arm to 
Asadi, A., \& Arazi, H. (2018). Relationship between test of postural control and strength and ability tests in basketball players. RICYDE. Revista internacional de ciencias del deporte, 52(14), 101-110.

https://doi.org/10.5232/ricyde2018.05201

measure their standing reach. The athletes were allowed to swing their arms and were instructed to jump as high as possible and reach for the vanes. To begin the test, the athletes stood in an upright standing position. When ready, they flexed at the ankles, knees, and hips to make a preliminary downward movement to a self-selected depth, then extended their ankles, knees, and hips to jump vertically. At the top of their jump, the athletes hit the vanes. Their vertical jump was measured as the difference between the highest vane hit on their jump and their standing reach. Athletes completed three jumps, and the best jump was used for analysis. For the BLJ, the athletes were required to stand with their toes behind the zero point of the tape measure prior to jumping. Each athlete initiated the jump with countermovement and arm swing. Each athlete jumped horizontally as far as possible and landed over the top of a tape measure secured to the floor. Distance was determined measuring the point at which the heel of the trial leg touched the ground. Athletes were given three trials, and the highest score was recorded for analysis. A 30-second break between trials was allowed for rest. The intraclass correlation coefficient (ICCs) for the CMJ and BLJ were 0.95 and 0.99 , respectively (Mirzaei et al., 2014).

Change of direction ability was measured by using $4 \times 9-\mathrm{m}$ shuttle run, t-test (TT), and Illinois agility test (IAT). For the shuttle run test, the athletes stood behind the starting line and on "GO" command, they started the 9-m run. At the end of the 9-m, the athletes were asked to stop with one foot beyond a marker while reversing the running direction and sprinting back to the start where the same reversing of movement direction was required. After the fourth 9$\mathrm{m}$, when the athletes crossed the finish line the time was stopped. The TT was applied as previously described 16, to determine change of direction speed (i.e., right and left sides), forward sprinting, and back-pedaling. Change of direction performance was also assessed with the IAT to determine the ability to accelerate, decelerate, turn in different directions, and run at different angles. This test has been described elsewhere. The timing system and procedures (handheld stopwatch, Joerex, ST4610-2, China) were the same for the tests. Three maximal trials were performed for all change of direction tests, with at least three min of rest between trials. The best time of the three maximal trials was selected for analysis. ICCs for the $4 \times 9-\mathrm{m}$ shuttle run, TT and IAT were $0.92,0.98$ and 0.94 , respectively (Mirzaei et al., 2014).

For the 20-m sprint test, the athletes performed three maximal effort sprints over the distance of $20-\mathrm{m}$. The sprint test was performed on a wood floor in the basketball gym. The athletes had standing start position on the start line, and on "GO" command they ran a 20-m sprint as fast as possible over the distance. The timing system and procedures were same as the change of direction tests. The ICC for the sprint test was 0.97 (Lockie et al., 2014).

For the strength test, each athlete was tested for maximal bilateral concentric one repetition leg-press $\left(1 \mathrm{RM}_{\mathrm{LP}}\right)$ using a leg press machine (Nebula Fitness, Inc., Versailles, $\left.\mathrm{OH}\right)$, following a previously described protocol (Kraemer and Fry, 1995). Briefly, athletes performed a warmup specific to this test consisting of eight to ten repetitions using a light weight, three to five repetitions using a moderate weight, and one to three repetitions using a heavy weight. Then, resistance was increased until participants were unable to complete an attempt using proper technique through a full range of motion. Up to five maximal attempts were allowed, with five minutes of rest between attempts. Spotters were present to provide verbal encouragement and ensure safety. The ICC for the $1 \mathrm{RM}_{\mathrm{LP}}$ was 0.93 . 
Asadi, A., \& Arazi, H. (2018). Relationship between test of postural control and strength and ability tests in basketball players. RICYDE. Revista internacional de ciencias del deporte, 52(14), 101-110.

The SEBT (Figure 2) is a test that incorporates a single-leg stance on one leg with maximum reach of the opposite leg. The test is consisted of 8 lines that make a $45^{\circ}$ angle to one another. The $45^{\circ}$ increments are from the center of the grid. The 8 lines positioned on the grid are labeled according to the direction of excursion relative to the stance leg (anterior [A], anterolateral $[\mathrm{AL}]$, anteromedial $[\mathrm{AM}]$, medial $[\mathrm{M}]$, lateral $[\mathrm{L}]$, posterior $[\mathrm{P}]$, posterolateral [PL], posteromedial [PM]). The diameter of the circle is $190 \mathrm{~cm}$ and it is placed on a wood surface. The width of each line is $5 \mathrm{~cm}$. In order to reduce the learning effect each subject chooses 6 directions out of the 8 to practice. The athlete stood in the middle of the circle with the dominant leg; then with the opposite leg he reached for the furthest marked distance. Each athlete was asked to touch the furthest part of the line with the most distal part of his reach foot. This was done with control and in a slow manner to ensure adequate neuromuscular control of the stance leg. The athlete then returned to the original stance and the touch points that were marked during examination were recorded. The direction of the revolution based on the right or left reach legs was clock wise and counter clock wise, respectively. The reach was not accepted if the leg could not touch the target line, if the athlete's weight was shifted to the reach leg, if the support leg was lifted from the center, or if balance was disturbed during the reach. Three second rest was allocated between each reach (Asadi et al., 2015; Lockie et al., 2013).

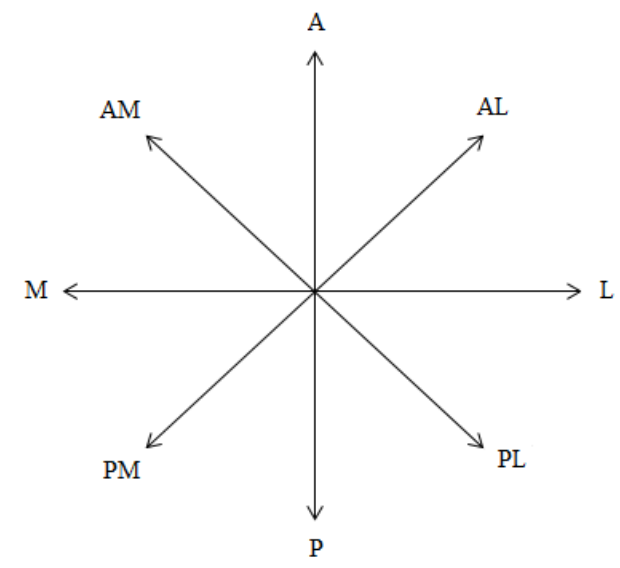

Right-leg stance

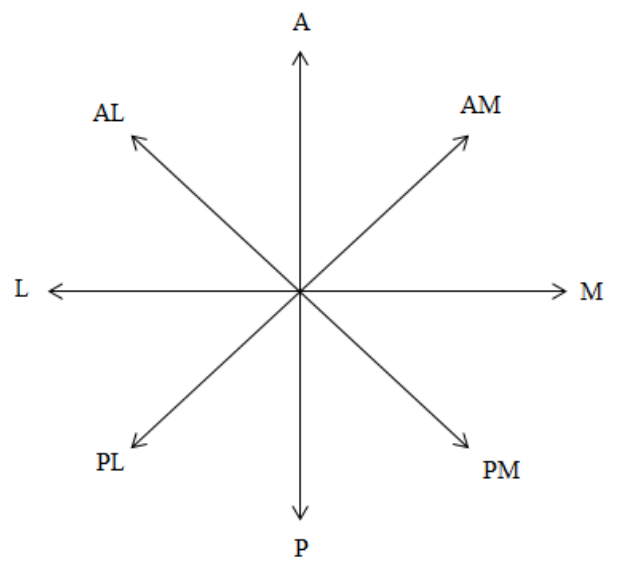

Left-leg stance

Figure 2. Star Excursion Balance Test procedure. A; anterior, AL; anterolateral, AM; anteromedial, M; medial, L; lateral, P; posterior, PL; posterolateral, PM; posteromedial.

\section{Statistical analysis}

The mean and standard deviation values for each test were calculated for all players. The distribution of each variable was examined using the Shapiro-Wilk test. The relationships between PC, jump performance, change of direction ability, sprint and lower extremity strength were analyzed using the Pearson Correlation Analysis $(r)$, with the level of statistical significance set at $p \leq 0.05$. The intraclass correlation coefficient (ICC) was used to determine the reliability of the measurements. 
Asadi, A., \& Arazi, H. (2018). Relationship between test of postural control and strength and ability tests in basketball players. RICYDE. Revista internacional de ciencias del deporte, 52(14), 101-110.

\section{Results}

Means and SDs are presented for all the variables in Table 1.

\begin{tabular}{lcc}
\multicolumn{4}{c}{ Table 1. Athletes postural control and exercise-performance tests. } \\
\hline Variables & Mean & \pm SD \\
\hline Postural control (SEBT) & 100.1 & \pm 4.4 \\
A (cm) & 100.7 & \pm 5.7 \\
AL (cm) & 93.2 & \pm 6.1 \\
L (cm) & 92.7 & \pm 7.8 \\
PL (cm) & 88.7 & \pm 8.8 \\
P (cm) & 84.0 & \pm 9.7 \\
PM (cm) & 77.1 & \pm 8.8 \\
M (cm) & 88.1 & \pm 7.4 \\
AM (cm) & & \\
Jump performance & 49.4 & \pm 7.0 \\
Countermovement jump (cm) & 224.4 & \pm 17.0 \\
Broad long jump (cm) & & \\
Change of direction ability & 9.5 & \pm 0.6 \\
4×9-m shuttle run (sec) & 11.6 & \pm 0.9 \\
Agility T test (sec) & 16.8 & \pm 0.7 \\
Illinois agility test (sec) & & \\
Sprint performance & 3.5 & \pm 0.2 \\
20-m sprint (sec) & & \\
Lower extremity strength & 192.1 & \pm 14.1 \\
1RM leg press & & \\
\hline
\end{tabular}

$\mathrm{SD}$ : standard deviation. $\mathrm{A}=$ anterior, $\mathrm{AL}=$ anterolateral, $\mathrm{L}=$ lateral, $\mathrm{PL}=$ posterolateral, $\mathrm{P}=$ posterior, $\mathrm{PM}=$ posteriomedial, $\mathrm{M}=$ medial, $\mathrm{AM}=$ Anteromedial.

No statistically significant correlations were detected between directions of SEBT and CMJ $(p>0.05)$. Whereas significant correlations were seen between BLJ and A $(p=0.025)$, AL $(p=0.021)$, and $\mathrm{L}(p=0.021)$ directions, respectively (Table 2$)$.

Among change of direction ability tests, the significant correlation were found between TT and $\mathrm{M}$ direction $(p=0.05)$, and between IAT and $\mathrm{A}(p=0.038)$ direction. Significant positive correlations were detected between $4 \times 9-\mathrm{m}$ shuttle run and A $(p=0.38) \mathrm{L}(p=0.019)$ and $\mathrm{M}$ $(p=0.05)$ directions, respectively (Table 2$)$.

Significant correlations were observed between sprint performance and directions of SEBT (i.e., $\mathrm{A} \mathrm{p}=0.30, \mathrm{AL} \mathrm{p}=0.017$, PL 0.05, and $\mathrm{M} \mathrm{p}=0.05$ ) (Table 2).

For the lower extremity strength performance, only in the $\mathrm{M}$ direction positive correlation $(\mathrm{p}=0.010)$ was found and in other directions the statistically significant correlations were not detected ( $\mathrm{p}>0.05)$ (Table 2). 
Asadi, A., \& Arazi, H. (2018). Relationship between test of postural control and strength and ability tests in basketball players. RICYDE. Revista internacional de ciencias del deporte, 52(14), 101-110.

Table 2. Correlations between postural control (SEBT) performance and maximal-intensity exercise performance tests.

\begin{tabular}{|c|c|c|c|c|c|c|c|c|}
\hline \multirow[t]{2}{*}{ Variables } & \multicolumn{8}{|c|}{ SEBT directions (cm) } \\
\hline & A & $\mathrm{AL}$ & $\mathrm{L}$ & PL & $\mathrm{P}$ & PM & $\mathrm{M}$ & $\mathrm{AM}$ \\
\hline \multicolumn{9}{|c|}{ Exercise performance tests } \\
\hline $\mathrm{CMJ}(\mathrm{cm})$ & $\mathrm{r}=-0.26$ & $\mathrm{r}=-0.11$ & $\mathrm{r}=-0.39$ & $\mathrm{r}=-0.06$ & $\mathrm{r}=-0.10$ & $\mathrm{r}=0.51$ & $\mathrm{r}=0.29$ & $\mathrm{r}=-0.17$ \\
\hline $\mathrm{BLJ}(\mathrm{cm})$ & $\mathrm{r}=-\mathbf{0 . 4 6}$ & $\mathrm{r}=-\mathbf{0 . 4 7}$ & $\mathrm{r}=-\mathbf{0 . 4 7}$ & $\mathrm{r}=-0.23$ & $\mathrm{r}=-0.08$ & $\mathrm{r}=-0.12$ & $\mathrm{r}=0.20$ & $\mathrm{r}=0.03$ \\
\hline 4×9-m shuttle run $(\mathrm{sec})$ & $\mathrm{r}=0.42$ & $\mathrm{r}=0.38$ & $\mathrm{r}=\mathbf{0 . 4 8}$ & $\mathrm{r}=0.24$ & $\mathrm{r}=0.20$ & $\mathrm{r}=0.08$ & $\mathrm{r}=-\mathbf{0 . 4 0}$ & $\mathrm{r}=0.05$ \\
\hline TT $(\sec )$ & $\mathrm{r}=0.33$ & $\mathrm{r}=0.25$ & $\mathrm{r}=0.35$ & $\mathrm{r}=0.16$ & $\mathrm{r}=0.01$ & $\mathrm{r}=0.07$ & $\mathrm{r}=-\mathbf{0 . 4 1}$ & $\mathrm{r}=-0.08$ \\
\hline IAT (sec) & $\mathrm{r}=\mathbf{0 . 4 3}$ & $\mathrm{r}=0.39$ & $\mathrm{r}=0.25$ & $\mathrm{r}=0.11$ & $\mathrm{r}=0.13$ & $\mathrm{r}=-0.14$ & $\mathrm{r}=-0.36$ & $\mathrm{r}=-0.23$ \\
\hline 20-m sprint (sec) & $\mathrm{r}=\mathbf{0 . 4 5}$ & $\mathrm{r}=\mathbf{0 . 4 9}$ & $\mathrm{r}=0.35$ & $\mathrm{r}=\mathbf{0 . 4 1}$ & $\mathrm{r}=0.22$ & $\mathrm{r}=0.18$ & $r=-\mathbf{0 . 4 0}$ & $\mathrm{r}=-0.02$ \\
\hline 1RM leg press (kg) & $\mathrm{r}=-0.32$ & $\mathrm{r}=-0.09$ & $\mathrm{r}=-0.20$ & $\mathrm{r}=-0.01$ & $\mathrm{r}=-0.17$ & $\mathrm{r}=0.27$ & $\mathrm{r}=\mathbf{0 . 5 2}$ & $\mathrm{r}=-0.03$ \\
\hline
\end{tabular}

Bold indicate positive correlations between directions of SEBT and performance measures at $\mathrm{p} \leq 0.05 . \mathrm{CMJ}=$ countermovement jump, BLJ $=$ broad long jump, $\mathrm{TT}=\mathrm{T}$ test, $\mathrm{IAT}=$ Illinois agility test, $1 \mathrm{RM}=1$ repetition maximum, $\mathrm{A}=$ anterior, $\mathrm{AL}=$ anterolateral, $\mathrm{L}=$ lateral, $\mathrm{PL}=$ posterolateral, $\mathrm{P}=$ posterior, $\mathrm{PM}=$ posteriomedial, $\mathrm{M}=$ medial, $\mathrm{AM}=$ Anteromedial.

\section{Discussion}

Performing successful actions in basketball require not only physical ability (i.e., sprint, strength, power and change of direction ability), but also dynamic balance or PC. Postural control allows athletes to maintain the center of gravity during sport-specific movement and deficits in PC induced falls or injuries (Bressel et al., 2007). However, little is known about the interaction between PC and maximal intensity exercise performance tests, especially in basketball players.

In accordance with the results of this study, Muehlbauer et al. (2013) did not find correlations between balance and CMJ. It seems that the performance of PC tasks and CMJ is independent of each other. In contrast, the positive associations were found between BLJ and A, AL, and L directions (Table 2). Regarding to horizontally based jump in BLJ, it seems that vastus muscles works greater than other side of leg muscles. More so, the similarity between A and AL directions and BLJ could be a reason for positive correlations between them. However, in this study muscle activation was not measured and it could be speculation.

The results of this study indicated that there were positive correlations between sprint and change of direction ability with PC performance. Previous authors reported that faster athletes in sprint and change of direction tests are more stable in balance tests and the rate of reaching directions are greater than others (Lockei et al., 2013). Significant correlations were found between $20 \mathrm{~m}$ sprint time and functional reach when considering excursion distance. Sprints within $20 \mathrm{~m}$ will generally encompass acceleration (Duthie et al., 2006). As the time spent in contact with the ground is longer during acceleration (Lockie et al., 2014), this may lessen the 
Asadi, A., \& Arazi, H. (2018). Relationship between test of postural control and strength and ability tests in basketball players. RICYDE. Revista internacional de ciencias del deporte, 52(14), 101-110.

https://doi.org/10.5232/ricyde2018.05201

impact of dynamic stability with the concurrent emphasis on force production during the initial stages of a sprint. However significant positive correlation with $20 \mathrm{~m}$ sprint time and A, AL, PL and M directions, indicating relationship between sprint and PC.

The correlation analyses documented significant, positive interactions between functional reach and the change of direction ability tests. Positive correlation was found between TT and $\mathrm{M}$ direction, IAT and A direction, and between $4 \times 9-\mathrm{m}$ shuttle run and $\mathrm{A}, \mathrm{L}$ and $\mathrm{M}$ directions. There is the activity of the vastus muscles of the stance leg for the reach excursions (Earl et al., 2001), and these muscles are essential for speed generation when running (Mann et al., 1986), which is a needed after a direction change. As stated, in the L and A excursions the abductor and vastus muscles are heavily recruited (Earl et al. 2001). The abductor and vastus muscles also help to facilitate braking and re-acceleration when changing direction, as well as increasing running speed (Kyrolainen et al., 2005). These results highlight the interaction between muscle groups in the legs, and how they may contribute to both dynamic stability and multidirectional speed or change of direction ability.

Lastly, this study indicated significant correlation between strength and PC (only in M direction) in basketball athletes. To data, a few studies tried to determine the relationship between strength and balance performance in athletes. For example, Thorpe and Ebersole (2008) indicated low to moderate correlations between SEBT performance and lower extremity strength. For the nonsoccer group, the $\mathrm{P}$ reach direction was the only direction with significant strength relationship. In the soccer group, the only significant correlation was between hip flexion and $\mathrm{P}$ reach. In the middle-aged adults the authors reported significant and nonsignificant correlations between balance and strength performance ( $r$ values between 0.66 and +0.90). Holviala et al. (2006) investigated the relationship between isometric strength and dynamic (i.e., 10-m walk time, 10 steps climbing time) balance in women. As a result, statistically significant correlations were found ranging from $r=-0.50$ to -0.60 . In contrast to that, Weirich et al. (2010) reported that most measures of dynamic (i.e., tandem walk) balance were only weakly or moderately related to quadriceps, hip extensor, and hamstring strength in middle-aged women. Based on the large variations in the size of correlations and their level of significance, it remains unclear whether balance and leg muscle strength are independent or dependent neuromuscular capacities. It is also possible that the absence of a relationship between strength and some directions of SEBT performance, in this study, may be attributable to the fact that there was not enough variance within the data to detect any relationship. However, more studies are necessary to show clear association between $\mathrm{PC} /$ balance performance and maximal intensity exercise performance tests in athletes.

In conclusion, the results of this study indicate relationship between PC and muscular performance. The PC performance is more in relation to change of direction ability, sprint performance and broad long jump. However, strength performance had a weak correlation with balance in one direction. The association between BLJ, but not CMJ, and PC indicate similar neuromuscular capacity. Although, in one direction positive correlation was found between strength and balance, these variables are independent of each other in basketball players. Strength and conditioning coaches in the field of basketball should keep in their mind that loss of muscular performance (i.e., sprint, jump and change of direction) is in line with balance deficits and this situation can probably increase falls and sport-related injuries. 
Asadi, A., \& Arazi, H. (2018). Relationship between test of postural control and strength and ability tests in basketball players. RICYDE. Revista internacional de ciencias del deporte, 52(14), 101-110.

\section{References}

Arendt, E., \& Dick, R. (1995). Knee injury patterns among men and women in collegiate basketball and soccer. NCAA data and review of literature. American Journal of Sports Medicine, 23, 694-701. https://doi.org/10.1177/036354659502300611

Asadi, A.; Saez de Villarreal, E., \& Arazi, H. (2015). The effects of plyometric type neuromuscular training on postural control performance of male team basketball players. Journal of Strength and Conditioning Research, 29(7), 1870-1875. https://doi.org/10.1519/JSC.0000000000000832

Bressel, E.; Yonker, J. C.; Kars, J., \& Heath, E.M. (2007). Comparison of static and dynamic balance in female collegiate soccer, basketball, and gymnastics athletes. Journal of Athletic Training, 42(1), 42-46.

Duthie, G.M.; Pyne, D. B.; Marsh, D. J., \& Hooper, S. L. (2006). Sprint patterns in rugby union players during competition. Journal of Strength and Conditioning Research, 20(1), 208-214.

Earl, J.E., \& Hertel, J. (2001). Lower-extremity muscle activation during the Star Excursion Balance Tests. Journal of Sports Rehabilitation, 10(2), 93-104. https://doi.org/10.1123/jsr.10.2.93

Erculj, F.; Blas, M., \& Bracic, M. (2010). Physical demands on young elite European female basketball players with special reference to speed, agility, explosive strength, and take-off power. Journal of Strength and Conditioning Research, 24(11), 29702978.

https://doi.org/10.1519/JSC.0b013e3181e38107

Fousekis, K.; Tsepis, E.; Poulmedis, P.; Athanasopoulos, S., \& Vagenas, G. (2011). Intrinsic risk factors of non-contact quadriceps and hamstring strains in soccer: $A$ prospective study of 100 professional players. British Journal of Sports Medicine, 45, 709-714.

https://doi.org/10.1136/bjsm.2010.077560

Holviala, J. H.; Sallinen, J. M.; Kraemer, W. J.; Markku, A., Häkkinen, K. (2006). Effects of strength training on muscle strength characteristics, functional capabilities, and balance in middle-aged and older women. Journal of Strength and Conditioning Research, 20(2), 336-344.

Khayambashi, K.; Goddosi, N.; Straub, R. K., \& Powers, C. M. (2016). Hip muscle strength predicts noncontact $\mathrm{ACL}$ injury in male and female athletes: A prospective study. American Journal of Sports Medicine, 44(2), 335-361.

https://doi.org/10.1177/0363546515616237

Kraemer, W. J., \& Fry, A. C. (1995). ACSM's Guidelines for Exercise Testing and Prescription, 6th ed, Champaign, IL, Human Kinetics.

Kyrolainen H, Avela J, Komi PV. (2005). Changes in muscle activity with increasing running speed. Journal of Sports Sciences, 23(10), 1101-1109. https://doi.org/10.1080/02640410400021575

Latin RW, Berg K, Baechle T. (1994). Physical and performance characteristics of NCAA Division I male basketball players. Journal of Strength and Conditioning Research, $8(3), 214-218$.

Lockie, R. G.; Schultz, A. B.; Callaghan, S. J.; Jeffriess, M. D., Berry, S. P. (2013). Reliability and validity of a new test of change-of-direction speed for field-based sports: the Change-of-Direction and Acceleration Test (CODAT). Journal of Sports Science and Medicine, 12(1), 88-96. 
Asadi, A., \& Arazi, H. (2018). Relationship between test of postural control and strength and ability tests in basketball players. RICYDE. Revista internacional de ciencias del deporte, 52(14), 101-110.

Lockie, R. G.; Schultz, A. B.; Callaghan, S.J., \& Jeffriess, M. D. (2014). The relationship between dynamic stability and multidirectional speed. Journal of Strength and Conditioning Research, 28(6), 1538-1551.

https://doi.org/10.1519/JSC.0000000000000309

MacDougall, D., \& Sale, D. (2014). The physiology of training for high performance. Oxford press.

Mann, R. A.; Moran, G.T., \& Dougherty, S. E. (1986). Comparative electromyography of the lower extremity in jogging, running, and sprinting. American Journal of Sports Medicine, 14(6), 501- 510. https://doi.org/10.1177/036354658601400614

McGuine, T. A.; Greene, J. J.; Best, T., \& Leverson, G. (2000). Balance as a predictor of ankle injuries in high school basketball players. Clinical Journal of Sports Medicine, 10(4), 239-244.

https://doi.org/10.1097/00042752-200010000-00003

Mirzaei, B.; Norasteh, A.; Saez de Villarreal, E., \& Asadi, A. (2014). Effects of 6 weeks of depth jump vs. countermovement jump training on sand on muscle soreness and performance. Kinesiology, 46(1), 97-108

Muehlbauer, T.; Gollhofer, A., \& Granacher, U. (2013). Association of balance, strength, and power measures in young adults. Journal of Strength and Conditioning Research, 27(3), 582-589.

https://doi.org/10.1519/JSC.0b013e31825c2bab

Myklebust, G.; Maehlum, S.; Engebretsen, L.; Strand, T., \& Solheim, E. (1997). Registration of cruciate ligament injuries in Norwegian top level team handball. A prospective study covering two seasons. Scandinavian Journal of Medicine and Science in Sports, 7(5), 289-292.

https://doi.org/10.1519/JSC.0b013e31825c2bab

Shalfawi, S. A. I.; Sabbah, A.; Kailani, G.; Tønnessen, E., \& Enoksen E. (2011). The relationship between running speed and measure of vertical jump in professional basketball players: a field-test approach. Journal of Strength and Conditioning Research, 25(11), 3088-3092.

https://doi.org/10.1519/JSC.0b013e318212db0e

Thorpe, J.L., \& Ebersole, K.T. (2008). Unilateral balance performance in female collegiate soccer athletes. Journal of Strength and Conditioning Research, 22(5), 1429-1433. https://doi.org/10.1519/JSC.0b013e31818202db

Wang, H. K.; Chen, C. H.; Shiang, T. Y; Jan, M. H., \& Lin, K. H. (2006). Risk factor analysis of high school basketball-player ankle injuries: A prospective controlled cohort study evaluating postural sway, ankle strength, and flexibility. Archive of Physical Medicine and Rehabilitation, 87(6), 821-825.

https://doi.org/10.1016/j.apmr.2006.02.024

Weirich, G.; Bemben, D. A., \& Bemben, M. G. (2010). Predictors of balance in young, middle-aged, and late middle-aged women. Journal of Geriatric Physical Therapy, $33(3), 110-117$. 